\title{
Simvastatin Alleviates Myocardial Contractile Dysfunction and Lethal Ischemic Injury in Rat Heart Independent of Cholesterol-Lowering Effects
}

\author{
A. ADAMEOVÁ ${ }^{1}$, A. HARČÁROVÁ ${ }^{1}$, J. MATEJÍKOVÁ, D. PANCZA, M. KUŽELOVÁ ${ }^{1}$, \\ S. ČARNICKÁ, P. ŠVEC ${ }^{1}$, M. BARTEKOVÁ, J. STYK, T. RAVINGEROVÁ
}

Institute for Heart Research, Slovak Academy of Sciences, Centre of Excellence for Cardiovascular Research of the SAS, Bratislava, and ${ }^{1}$ Department of Pharmacology and Toxicology, Faculty of Pharmacy Comenius University, Bratislava, Slovak Republic

Received January 23, 2009

Accepted March 16, 2009

\section{Summary}

Statins, the inhibitors of 3-hydroxy-3-methylglutaryl coenzyme A (HMG-COA) reductase, are most frequently used drugs in the prevention of coronary artery disease due to their cholesterollowering activity. However, it is not exactly known whether these effects of statins or those independent of cholesterol decrease account for the protection against myocardial ischemiareperfusion (I/R) injury. In this study, we investigated the effect of 5-day treatment with simvastatin $(10 \mathrm{mg} / \mathrm{kg})$ in Langendorffperfused hearts of healthy control (C) and diabetichypercholesterolemic (D-H; streptozotocin + high fat-cholesterol diet, 5 days) rats subjected to 30 -min global ischemia followed by $40-\mathrm{min}$ reperfusion for the examination of postischemic contractile dysfunction and reperfusion-induced ventricular arrhythmias or to 30-min (left anterior descending) coronary artery occlusion and 2 -h reperfusion for the infarct size determination (IS; tetrazolium staining). Postischemic recovery of left ventricular developed pressure (LVDP) in animals with D-H was improved by simvastatin therapy $(62.7 \pm 18.2 \%$ of preischemic values vs. $30.3 \pm 5.7 \%$ in the untreated $\mathrm{D}-\mathrm{H}$; $\mathrm{P}<0.05)$, similar to the values in the simvastatin-treated $\mathrm{C}$ group, which were 2.5 -fold higher than those in the untreated $C$ group. No ventricular fibrillation occurred in the simvastatin-treated $\mathrm{C}$ and D-H animals during reperfusion. Likewise, simvastatin shortened the duration of ventricular tachycardia $(10.2 \pm 8.1 \mathrm{~s}$ and $57.8 \pm 29.3 \mathrm{~s}$ in C and D-H vs. $143.6 \pm 28.6 \mathrm{~s}$ and $159.3 \pm 44.3 \mathrm{~s}$ in untreated $\mathrm{C}$ and $\mathrm{D}-\mathrm{H}$, respectively, both $\mathrm{P}<0.05$ ). The decreased arrhythmogenesis in the simvastatin-treated groups correlated with the limitation of IS (in \% of risk area) by $66 \%$ and $62 \%$ in $\mathrm{C}$ and D-H groups, respectively. However, simvastatin treatment decreased plasma cholesterol levels neither in the $\mathrm{D}-\mathrm{H}$ animals nor in $\mathrm{C}$. The results indicate that other effects of statins (independent of cholesterol lowering) are involved in the improvement of contractile recovery and attenuation of lethal $I / R$ injury in both, healthy and diseased individuals.

\section{Key words}

Statins • Cholesterol • Pleiotropic effects • Heart • Ischemia

\section{Corresponding author}

T. Ravingerová, Institute for Heart Research, Slovak Academy of Sciences, POB 104, Dúbravská cesta 9, 84005 Bratislava, Slovak Republic. Fax: +421 25477 6637. E-mail: usrdravi@savba.sk

It is generally known that statins, inhibitors of 3-hydroxy-3-methylgluratyl CoA reductase, reduce cardiovascular morbidity and mortality due to cholesterol-lowering effects (Gould et al. 2007). However, other lipid-independent pleiotropic actions may contribute to cardioprotection induced by statins (Takemoto and Liao 2001, McFarlane et al. 2002) that has been documented in experimental studies demonstrating a decrease in oxidative stress (Zhou et al. 2008, Kuželová et al. 2008), inflammation (van Linthout et al. 2007, Endres 2006), inhibition of thrombogenic response (Rossoni et al. 2008, Schafer et al. 2006) and atherosclerotic plaque formation (Shimizu et al. 2003, 
Table 1. The effects of 5-day simvastatin (S) treatment on plasma levels of glucose (Glu) and total cholesterol (Chol) in normal control (C) and diabetic-hypercholesterolemic (D-H) rats.

\begin{tabular}{|c|c|c|c|c|}
\hline & $\begin{array}{l}\text { C } \\
n=9\end{array}$ & $\begin{array}{l}\mathbf{C}+\mathbf{S} \\
n=7\end{array}$ & $\begin{array}{l}\text { D-H } \\
n=8\end{array}$ & $\begin{array}{l}\text { D-H+S } \\
n=7\end{array}$ \\
\hline Glu (mmol/l) & $5.52 \pm 0.63$ & $5.28 \pm 0.50$ & $17.85 \pm 2.50 \dagger$ & $13.83 \pm 1.11 \dagger$ \\
\hline Chol (mmol/l) & $1.51 \pm 0.11$ & $1.62 \pm 0.21$ & $2.50 \pm 0.19 \dagger$ & $2.18 \pm 0.16 \dagger$ \\
\hline
\end{tabular}

Values are means \pm S.E.M. of 7-9 animals per group. $\dagger \mathrm{P}<0.05$ vs. respective normocholesterolemic controls.

Monettie et al. 2007) resulting in attenuation of vascular endothelial dysfunction. The mechanisms responsible for pleiotropic effects of statins involve inhibition of important intermediates, small GTP-binding proteins, such as Ras, Rho, and Rac, which modulate a wide variety of cellular processes (Takemoto and Liao 2001) including myocardial response to ischemia-reperfusion (I/R) injury. In our previous study performed in the openchest diabetic-hypercholesterolemic rats (D-H), simvastatin pretreatment significantly reduced reperfusion arrhythmias occurring after regional ischemia (Adameová et al. 2006). In this study in the isolated Langendorff-perfused rat hearts we focused on the effects of simvastatin on the myocardial infarct size (IS), as well as postischemic recovery of contractile function and reperfusion arrhythmias. To elucidate whether effects of simvastatin on I/R injury are dependent on cholesterol lowering, we compared its effects in both, D-H rats and normocholesterolemic animals.

Male Wistar rats (250-300 g body weight), fed a standard diet and tap water ad libitum, were employed. All studies were performed in accordance with the Guide for the Care and Use of Laboratory Animals published by US National Institutes of Health (NIH publication No 85-23, revised 1996).

Simvastatin was given at the dose of $10 \mathrm{mg} / \mathrm{kg}$ as a component of the normal and/or a high-cholesterol diet to the healthy control (C) and double-diseased D-H rats, respectively. The choice of the dosage was based upon the results of some previous studies, which have used the same or even higher dose of statins administered orally (Birnbaum et al. 2003, Tavackoli et al. 2004). The D-H state was induced with streptozotocin $(80 \mathrm{mg} / \mathrm{kg}$, i.p.) and administration of high-cholesterol diet (1\% cholesterol, $1 \%$ cocounut oil; $20 \mathrm{~g} / \mathrm{kg}$ per day) as described earlier (Adameová et al. 2006, 2007a).

Following 5 days, the hearts of anesthetized (sodium pentobarbitone, $60 \mathrm{mg} / \mathrm{kg}$, i.p.) $\mathrm{C}$ and $\mathrm{D}-\mathrm{H}$ animals were rapidly excised and perfused at $37{ }^{\circ} \mathrm{C}$ in the
Langendorff mode at a constant perfusion pressure of $70 \mathrm{~mm} \mathrm{Hg}$. The perfusion solution was a modified KrebsHenseleit buffer gassed with $95 \% \mathrm{O}_{2}$ and $5 \% \mathrm{CO}_{2}$ (pH 7.4) containing (in $\mathrm{mM}$ ): $\mathrm{NaCl} 118.0 ; \mathrm{KCl} 3.2$; $\mathrm{MgSO}_{4}$ 1.2; $\mathrm{NaHCO}_{3}$ 25.0; $\mathrm{KH}_{2} \mathrm{PO}_{4}$ 1.18; $\mathrm{CaCl}_{2}$ 2.5; glucose 7.0. An epicardial electrogram was registered by means of two electrodes attached to the apex of the heart and the aortic cannula. Left ventricular (LV) pressure was measured by means of a non-elastic water-filled balloon inserted into the LV cavity and connected to a pressure transducer (MLP844, ADInstruments). LV developed pressure (LVDP; systolic minus diastolic pressure), maximal rates of pressure development and fall, heart rate, pressure-rate product and coronary flow were measured during stabilization pre-ischemic period and continuously recorded until the end of experiment. Heart function and arrhythmias were analyzed using PowerLab/8SP Chart 5 software (ADInstruments).

Global ischemia was induced by clamping of aortic inflow for $30 \mathrm{~min}$ and followed by 40-min reperfusion for the evaluation of postischemic recovery of LVDP expressed as percentage of preischemic baseline values and of susceptibility to reperfusion-induced ventricular tachyarrhythmias, such as ventricular fibrillation (VF) and tachycardia (VT).

For the evaluation of IS, in the additional subset of experiments the hearts underwent regional test ischemia induced by left anterior descending coronary artery occlusion for $30 \mathrm{~min}$ followed by 2-h reperfusion. The IS and area at risk (AR) size was delineated by double staining with $5 \%$ potassium permanganate and 2,3,5-triphenyltetra-zolium chloride and determined by a computerized planimetric method as described earlier (Ravingerová et al. 2007). The IS was expressed as percentage of the AR area.

The plasma glucose and cholesterol levels were measured enzymatically using a commercial assay kit (Spinreact, USA) and bioanalyzer ELISA 200 (USA) (Adameová et al. 2006, 2007a). 
The data were expressed as means \pm S.E.M. One-way ANOVA and subsequent Student-NewmanKeuls test as well as Mann-Whitney U test were used where appropriate. Differences were considered as significant at $\mathrm{P}<0.05$.

The D-H state was confirmed by significantly increased plasma glucose and total cholesterol levels. Simvastatin decreased the plasma cholesterol levels neither in D-H nor in C animals (Table 1). Furthermore, no significant changes were observed in the plasma glucose levels between the treated and respective untreated animal groups (Table 1).

Despite development of $\mathrm{D}-\mathrm{H}$, no significant differences in the values of coronary flow and ventricular hemodynamic parameters between $\mathrm{C}$ and $\mathrm{D}-\mathrm{H}$ groups were observed at baseline before ischemia. Administration of simvastatin did not affect these parameters in any of the groups (data not shown).

On the other hand, 5-day acute simvastatin administration to the $\mathrm{D}-\mathrm{H}$ rats increased post-ischemic recovery of LVDP $(62.7 \pm 18.2 \%$ of preischemic values vs. $30.3 \pm 5.7 \%$ in untreated $\mathrm{D}-\mathrm{H}$; $\mathrm{P}<0.05$; Fig. 1). Likewise, in $\mathrm{C}$ group, simvastatin improved LVDP recovery from $24.1 \pm 2.9 \%$ to $76.1 \pm 9.8 \% ; \mathrm{P}<0.05$; Fig. 1). Interestingly, no worsening of the left ventricle function was documented in the D-H rats as compared with the $\mathrm{C}$ animals. Similarly, the size of myocardial infarction in these animals did not differ from that in the normocholesterolemic ones (IS/AR 37.3 $\pm 3.1 \%$ in D-H vs. $33.7 \pm 4.0 \%$ in $\mathrm{C}$; $\mathrm{P}>0.05)$, but was higher in comparison with IS observed in normocholesterolemic rats in the acute phase of diabetes showing lower susceptibility to I/R injury (Adameová et al. 2007a). Simvastatin therapy significantly reduced infarct size in both groups (IS/AR $14.2 \pm 1.3 \%$ and $11.5 \pm 0.4 \%$ in D-H and $\mathrm{C}$, respectively; both $\mathrm{P}<0.05$; Fig. 1). A lower infarct size in the simvastatin-treated animals correlated with the severity of arrhythmogenesis; a shorter duration of VT was observed in both treated groups of $\mathrm{D}-\mathrm{H}$ and $\mathrm{C}$ animals $(10.2 \pm 8.1 \mathrm{~s}$ and $57.8 \pm 29.3 \mathrm{~s}$ vs. $143.6 \pm 28.6 \mathrm{~s}$ and $159.3 \pm 44.3 \mathrm{~s}$ in the untreated $\mathrm{C}$ and $\mathrm{D}-\mathrm{H}$, respectively, both $\mathrm{P}<0.05$; Fig. 1).

The present study demonstrated that both electrical and mechanical myocardial function may be influenced by statins independently of cholesterollowering not only in the healthy but also in the diseased D-H animals. Acute simvastatin therapy for 5 days showed hypolipidemic effects neither in the normal nor in the double-diseased rats. However, when measured in
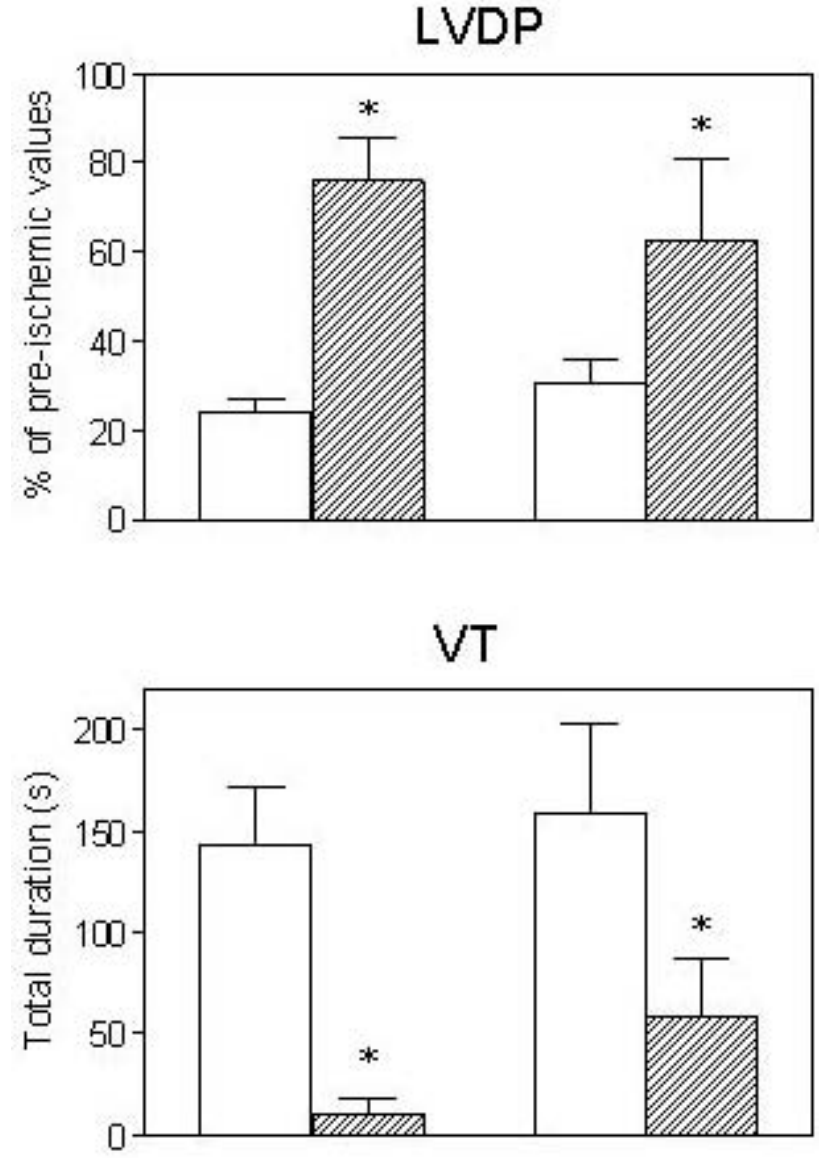

Infarct size

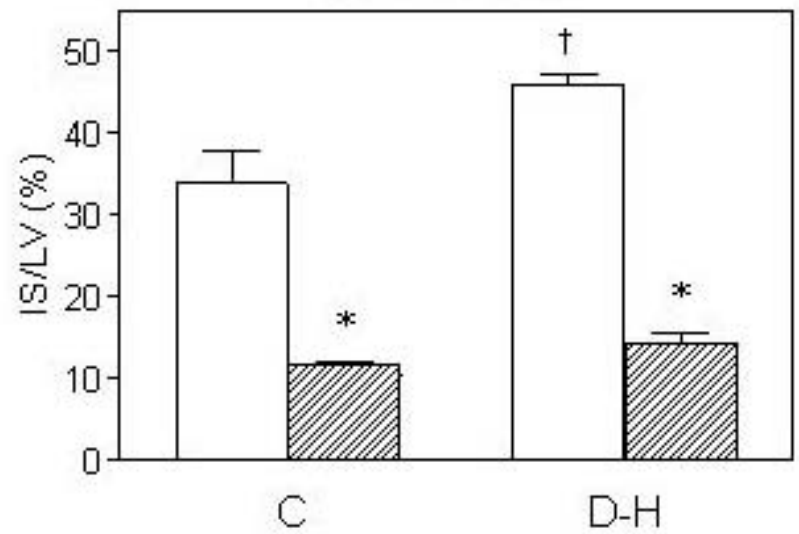

Fig. 1. Effect of 5-day simvastatin treatment on postischemic recovery of left ventricular developed pressure (LVDP), duration of ventricular tachycardia (VT) and size of infarction (IS) expressed as percentage of area at risk (AR) size in the hearts of normal (C) and diabetic-hypercholesterolemic (D-H) rats. Empty bars, untreated rats; filled bars, treated rats. Values are means \pm S.E.M. from $8-10$ hearts per group. * $\mathrm{P}<0.05$ vs. untreated group.

the liver, simvastatin normalized the higher cholesterol content induced by the fat-cholesterol diet and diabetes (Adameová et al. 2006). 
Although it is known that statins may reduce the glucose levels (McFarlane et al. 2002) and the administration of simvastatin for 10 days has decreased plasma glucose levels in the D-H rats (Adameová et al. 2007b), in the present study we did not observe the hypoglycemic effects. The results of our study indicate that pleiotropic effects of statins might account for decreased outcome of myocardial I/R. It is thus probable that statin-induced attenuation of oxidative stress (Zhou et al. 2008, Kuželová et al. 2008) and/or inflammatory response (Van Linthout et al. 2007, Endres 2006) involved in the genesis of I/R injury (Ravingerová et al. 1999) may explain the observed antiarrhythmic effects and IS limitation. In addition, activation of prosurvival cascade PI3K/Akt has been found to occur as a consequence of treatment with statins (Wang et al. 2007). Administration of statins prior to the onset of myocardial ischemia up-regulated the levels of phosphorylated Akt and exerted preconditioning-like infarct size-limiting effect (Sanada et al. 2004, Manickavasagam et al. 2007) that has been explained by Akt-mediated activation of eNOS and another downstream molecule 5'-nucleotidase (Sanada et al. 2004, Efthymiou et al. 2005). It has also been suggested that the PI3K/Akt pathway and an increase of eNOS resulting in the increased cappilary recruitment and glucose disposal may account for the hypoglycemic effects of statins (McFarlane et al. 2002). However, hypoglycemic activity of statins seems to be specific only for some of them. In fact, pravastatin, unlike atorvastatin, has been shown to exert beneficial effects on glucose metabolism (Ishikawa et al. 2006). Moreover, non-lipid action of statins also seems to contribute to the alleviation of postischemic contractile dysfunction in both healthy and diseased animals. Better LVDP recovery in addition to the inhibition of enzymes characterizing myocardial cell damage (e.g. creatine kinase, lactate dehydrogenase) in the treated normocholesterolemic rats was achieved even with the lower doses of simvastatin (Rossoni et al. 2008). However, in that study simvastatin was given by gavage, whereas we used it as a component of the food. It should be pointed out that such myocardial protection against $\mathrm{I} / \mathrm{R}$ is accomplished by a short-term but not a long-term statin therapy (Birnbaum et al. 2007, Tiefenbacher et al. 2003, Wayman et al. 2003). In fact, statins failed to reduce infarct size and to increase postischemic functional recovery when administered for more than one week (Mensah et al. 2005, Szárszoi et al. 2008). Here we also observed a lower infarct size in addition to a significantly shorter duration of VT in both acute simvastatin-treated groups. This is in line with our study in the normocholesterolemic rats demonstrating simvastatin-induced protection against ischemic arrhythmias (Ravingerová et al. 2008). Moreover, lethal arrhythmias (sustained VF) occurred neither in the simvastatin-treated normocholesterolemic nor in the D-H animals (data not shown). These findings are in accordance with the results of our previous study performed in the open-chest D-H animals; the severity of reperfusion ventricular arrhythmias occurring after regional ischemia was significantly decreased (Adameová et al. 2006). From the foregoing discussion it appears that short-term statin therapy might be a prospective strategy used for mitigation of the outcome of cardiac surgeries linked with reperfusion injury. Another non-lipid lowering indication of statins suggested partially also by results of this study could be their using in the pathological conditions such as myocardial ischemia, hypertrophy and heart failure (Liao 2004).

In conclusion, 5-day treatment with simvastatin improved postischemic recovery of myocardial function, suppressed the severity of reperfusion-induced tachyarrhythmias and attenuated lethal injury in the hearts of both, normal and diabetic-hypercholesterolemic rats without normalizing plasma levels of cholesterol. The latter indicates that other than cholesterol-lowering effects of simvastatin are involved in its cardioprotective action.

\section{Conflict of Interest}

There is no conflict of interest.

\section{Acknowledgements}

The authors are thankful to Mrs. J. Haššová, I. Blažíčková, and I. Formánková for their excellent technical assistance. This study was supported by grants VEGA SR 1/0357/09, 1/4296/07, 2/0173/08, 2/7126/27 and APVV 0538-07.

\section{References}

ADAMEOVÁ A, KUŽELOVÁ M, FÁBEROVÁ V, SVEC P: Protective effect of simvastatin and VULM 1457 in ischaemic-reperfused myocardium of the diabetic-hypercholesterolemic rats. Pharmazie 61: 807-808, 2006. 
ADAMEOVÁ A, KUŽELOVÁ M, ANDĚLOVÁ E, FÁBEROVÁ V, PANCZA D, ŠVEC P, ZIEGELHÖFFER A, RAVINGEROVÁ T: Hypercholesterolemia abrogates an increased resistance of diabetic rat hearts to ischemia-reperfusion injury. Mol Cell Biochem 295: 129-136, 2007a.

ADAMEOVÁ A, SUMBALOVÁ Z, ŠVEC P, KUCHARSKÁ J, KUŽELOVÁ M: The increased myocardial coenzyme $\mathrm{Q}$ content in the diabetic-hypercholesterolaemic rats is reduced by simvastatin therapy. Biomed Pap 151: 3-5, 2007b.

BIRNBAUM Y, ASHITKOV T, URETSKY BF, BALLINGER S, MOTAMEDI M. Reduction of infarct size by shortterm pretreatment with atorvastatin. Cardiovasc Drugs Ther 17: 25-30, 2003.

BIRNBAUM Y, LIN Y, YE Y, MARTINEZ JD, HUANG MH, LUI CY, PEREZ-POLO JR, URETSKY BF: Aspirin before reperfusion blunts the infarct size limiting effect of atorvastatin. Am J Physiol 292: H2891-H2897, 2007.

EFTHYMIOU CA, MOCANU MM, YELLON DM: Atorvastatin and myocardial reperfusion injury: new pleiotropic effect implicating multiple prosurvival signaling. J Cardiovasc Pharmacol 45: 247-252, 2005.

ENDRES M: Statins: potential new indications in inflammatory conditions. Atherosclerosis Suppl 7: 31-35, 2006.

GOULD AL, DAVIES GM, ALEMAO E, YIN DD, COOK JR: Cholesterol reduction yields clinical benefits: metaanalysis including recent trials. Clin Ther 29: 778-794, 2007.

CHEN J, NAGASAWA Y, ZHU BM, OHMORI M, HARADA K, FUJIMURA A, HASHIMOTO K: Pravastatin prevents arrhythmias induced by coronary artery ischemia/reperfusion in anesthetized normocholesterolemic rats. J Pharmacol Sci 93: 87-94, 2003.

IKEDA Y, YOUNG LH, LEFER AM: Rosuvastatin, a new HMG-CoA reductase inhibitor, protects ischemic reperfused myocardium in normocholesterolemic rats. J Cardiovasc Pharmacol 41: 649-656, 2003.

KUŽELOVÁ M, ADAMEOVÁ A, SUMBÁLOVÁ Z, PAULÍKOVÁ I, HARCAROVÁ A, ŠVEC P, KUCHARSKÁ J: The effect of simvastatin on coenzyme $\mathrm{Q}$ and antioxidant/oxidant balance in diabetic-hypercholesterolaemic rats. Gen Physiol Biophys 27: 291-298, 2008.

LIAO JK: Statin therapy for cardiac hypertrophy and heart failure. J Investig Med 52: 248-253, 2004.

MCFARLANE SI, MUNIYAPPA R, FRANCISCO R, SOWERS JR: Pleiotropic effects of statins: lipid reduction and beyond. J Clin Endocrinol Metab 87:1451-1458, 2002.

MANICKAVASAGAM S, YE Y, LIN Y, PEREZ-POLO RJ, HUANG M-H, LUI CY, HUGHES MG, MCADOO DJ, URETSKY BF, BIRNBAUM Y: The cardioprotective effect of Matsui T a statin and cilostazol combination: relationship to Akt and endothelial nitric oxide synthase activation. Cardiovasc Drugs Ther 21: 323-330, 2007.

MATAFOME P, MONTEIRO P, NUNES E, LOURO T, AMARAL C, MOEDAS AR, GONÇALVES L, PROVIDÊNCIA L, SEIÇA R: Therapeutic association of atorvastatin and insulin in cardiac ischemia: study in a model of type 2 diabetes with hyperlipidemia. Pharmacol Res 58: 208-214, 2008.

MENSAH K, MOCANU MM, YELLON DM: Failure to protect the myocardium against ischemia/reperfusion injury after chronic atorvastatin treatment is recaptured by acute atorvastatin treatment: a potential role for phosphatase and tensin homolog deleted on chromosome ten? J Am Coll Cardiol 45: 1287-1291, 2005.

MONETTI M, CANAVESI M, CAMERA M, PARENTE R, PAOLETTI R, TREMOLI E, CORSINI A, BELLOSTA S: Rosuvastatin displays anti-atherothrombotic and anti-inflammatory properties in apoE-deficient mice. Pharmacol Res 55: 441-449, 2007.

RAVINGEROVÁ T, ADAMEOVÁ A, MEGRAJ VK, ZÁZRIVCOVÁ M, MATEJÍKOVÁ J, ONDREJČÁKOVÁ M, PANCZA D, STYK J: The effects of simvastatin on the size of myocardial infarction and ventricular arrhythmias in the rat heart. Physiol Res 57: 27P, 2008.

RAVINGEROVÁ T, SLEZÁK J, TRIBULOVÁ J, DŽURBA A, UHRÍK B, ZIEGELHÖFFER A: Reactive oxygen species contribute to high incidence of reperfusion-induced arrhythmias in isolated rat heart. Life Sci 65: 19271930, 1999.

ROSSONI G, MANFREDI B, CIVELLI M, BERTI F, RAZZETTI R: Combined simvastatin-manidipine protect against ischemia-reperfusion injury in isolated hearts from normocholesterolemic rats. Eur J Pharmacol 587: 224-230, 2008. 
SANADA S, ASANUMA H, MINAMINO T, NODE K, TAKASHIMA S, OKUDA H, SHINOZAKI Y, OGAI A, FUJITA M, HIRATA A, KIM J, ASANO Y, MORI H, TOMOIKE H, KITAMURA S, HORI M, KITAKAZE M: Optimal windows of statin use for immediate infarct limitation: 5'-nucleotidase as another downstream molecule of phosphatidylinositol 3-kinase. Circulation 110, 2143-2149, 2004.

SCALIA R, GOOSZEN ME, JONES SP, HOFFMEYER M, RIMMER DM 3RD, TROCHA SD, HUANG PL, SMITH MB, LEFER AM, LEFER DJ: Simvastatin exerts both anti-inflammatory and cardioprotective effects in apolipoprotein E-deficient mice. Circulation 103: 2598-2603, 2001.

SHIMIZU K, AIKAWA M, TAKAYAMA K, LIBBY P, MITCHELL RN: Direct anti-inflammatory mechanisms contribute to attenuation of experimental allograft arteriosclerosis by statins. Circulation 108: 2113-2120, 2003.

SCHAFER A, FRACCAROLLO D, EIGENTHALER M, TAS P, FIRNSCHILD A, FRANTZ S, ERTL G, BAUERSACHS J: Rosuvastatin reduces platelet activation in heart failure: role of NO bioavailability. Arterioscler Thromb Vasc Biol 25: 1071-1077, 2005.

SZÁRSZOI O, MALÝ J, OŠŤÁDAL P, NETUKA I, BEŠÍK J, KOLÁŘ F, OŠŤÁDAL B: Effect of acute and chronic simvastatin treatment on post-ischemic contractile dysfunction in isolated rat heart. Physiol Res 57: 793-796. 2008.

TAKEMOTO M, LIAO JK: Pleiotropic effects of 3-hydroxy-3-methylglutaryl coenzyme a reductase inhibitors. Arterioscler Thromb Vasc Biol 21: 1712-1719, 2001.

TAVACKOLI S, ASHITKOV T, HU ZY, MOTAMEDI M, URETSKY BF, BIRNBAUM Y. Simvastatin-induced myocardial protection against ischemia-reperfusion injury is mediated by activation of ATP-sensitive $\mathrm{K}^{+}$ channels. Coron Artery Dis 15: 53-58, 2004.

TIEFENBACHER CP, KAPITZA J, DIETZ V, LEE CH, NIROOMAND F: Reduction of myocardial infarct size by fluvastatin. Am J Physiol 285: H59-H64, 2003.

UEDA Y, KITAKAZE M, KOMAMURA K, MINAMINO T, ASANUMA H, SATO H, KUZUYA T, TAKEDA H, HORI M: Pravastatin restored the infarct size-limiting effect of ischemic preconditioning blunted by hypercholesterolemia in the rabbit model of myocardial infarction. J Am Coll Cardiol 34: 2120-2125, 1999.

VAN LINTHOUT S, RIAD A, DHAYAT N, SPILLMANN F, DU J, DHAYAT S, WESTERMANN D, HILFIKERKLEINER D, NOUTSIAS M, LAUFS U, SCHULTHEISS HP, TSCHÖPE C: Anti-inflammatory effects of atorvastatin improve left ventricular function in experimental diabetic cardiomyopathy. Diabetologia 50: 1977 1986, 2007.

WANG CY, LIU PY, LIAO JK: Pleiotropic effects of statin therapy: molecular mechanisms and clionical results. Trends Mol Med 14: 37-44, 2007.

WAYMAN NS, ELLIS BL, THIEMERMANN C: Simvastatin reduces infarct size in a model of acute myocardial ischemia and reperfusion in the rat. Med Sci Monit 9: BR155-159, 2003.

ZHOU R, XU Q, ZHENG P, YAN L, ZHENG J, DAI G: Cardioprotective effect of fluvastatin on isoproterenolinduced myocardial infarction in rat. Eur J Pharmacol 586: 244-250, 2008. 